Revista de
Economild
Contemporâned

\title{
ESCOLARIDADE E DISTRIBUIÇÃO DE RENDA ENTRE OS EMPREGADOS NA ECONOMIA BRASILEIRA: UMA ANÁLISE COMPARATIVA DOS SETORES PÚBLICO E PRIVADO DOS ANOS 2001 E 2013
}

\author{
Daniel da Silva Barros ${ }^{a}$ \\ aprofessor Associado da Universidade Estadual de Londrina. \\ Artigo recebido em 14/01/2017 e aprovado em 24/11/2017.
}

RESUMO: O objetivo deste trabalho é analisar a influência da escolaridade na distribuição da renda entre os empregados dos setores público e privado na economia brasileira nos anos 2001 e 2013. A metodologia utilizada foi a decomposição do Índice de Gini, tanto por fontes de renda quanto por grupamentos de atividades de trabalho. Foi utilizado o software Stata como instrumento para o processamento dos microdados disponibilizados pela Pesquisa Nacional por Amostra de Domićlios - PNAD/IBGE. Verificou-se que, entre 2001 e 2013, houve uma redução da desigualdade da distribuição de renda da economia e o Índice de Gini caiu de 0,571 para 0,506, ocorrendo um aumento na razão de concentração no rendimento do funcionalismo público, que é uma parcela regressiva e houve uma diminuição na razão de concentração do rendimento dos empregados do setor privado, que é uma parcela de renda progressiva. Detectou-se, também, que as mulheres têm mais anos de estudos do que os homens, em média 1,3 anos a mais. Porém, o rendimento médio feminino é $22,0 \%$ inferior em relação ao rendimento médio masculino; esta diferença era mais acentuada em 2001, tanto nos anos de estudo como no rendimento.

PALAVRAS-CHAVE: desigualdade; setor privado; funcionários públicos; renda dos empregados.

CLASSIFICAÇÃO JEL: D33; E25; I24.

Correspondência para: Daniel da Silva Barros

Contato: dbarros@uel.br 


\title{
SCHOOLING AND DISTRIBUTION OF INCOME
}

\section{BETWEEN EMPLOYEES IN THE BRAZILIAN ECONOMY: A COMPARATIVE ANALYSIS OF THE PUBLIC AND PRIVATE SECTORS OF THE YEARS 2001 AND 2013}

\begin{abstract}
The objective of this study is to analyze the influence of education on income distribution among employees in the public and private sectors in the Brazilian economy in 2001 and 2013. The methodology used is the decomposition of the Gini Index, both sources of income as by groups of work activities. We use the Stata software as a tool for processing the micro data released by the National Sample Survey of Households - PNAD / IBGE. It appears that between 2001 and 2013 there was a reduction in inequality of income distribution in the economy, the Gini index fell from 0.571 to 0.506. An increase in the concentration ratio in the civil service revenue, which is a regressive parcel; and there was a decrease in the concentration ratio of the income of employees in the private sector, which is a portion of progressive income. It is detected, too, that women have more years of schooling than men, on average 1.3 years longer. However, women's average income is $22.0 \%$ lower than the average male income; this difference was more pronounced in 2001 , both years of study as in revenue.
\end{abstract}

KEYWORDS: inequality; private sector; public workers; income employees. 


\section{INTRODUÇÃO}

A educação é um fator indispensável para que haja desenvolvimento econômico. Mesmo que haja crescimento do Produto Agregado impulsionado por outros fatores, isto não significa que o desenvolvimento será disseminado, se o ambiente for repleto de pessoas com baixos níveis de escolaridade, desinformadas ou analfabetas. É impossível uma nação buscar o desenvolvimento sem priorizar a educação, especialmente, no caso de economias mais atrasadas, implementando políticas sociais com a intenção de retirar uma parcela da população do estágio de exclusão social, o que serve apenas como medidas paliativas de curto prazo, sem efeito positivo para o desenvolvimento sustentável da economia em longo prazo.

Uma característica indesejável do sistema de educação brasileiro é a alta desigualdade educacional, embora apresente um nível médio de escolaridade muito baixo, mesmo quando comparado ao de outros países com padrão de renda per capita e desenvolvimento semelhante ao do Brasil. Lam e Levison (1990) estimaram uma variância de anos de escolaridade entre brasileiros do sexo masculino em $70 \%$ mais alta que a dos homens nos Estados Unidos, no entanto, a escolaridade média dos brasileiros representa apenas a metade daquela apresentada pelos norte-americanos.

A principal fonte de informações para estudos sobre a desigualdade de renda é as pesquisas domiciliares com representatividade nacional que, apesar de sua qualidade e abrangência, apresentam algumas limitações na mensuração da renda comuns às pesquisas desse tipo, as quais podem dificultar a análise da desigualdade de renda. Este trabalho utilizará a Pesquisa Nacional por Amostra de Domicílios (PNAD), que anualmente é realizada pelo IBGE e possibilita a realização de análise sobre a evolução da distribuição de rendas no Brasil. Hoffmann e Ney (2008a) evidenciam que é razoável considerar algum grau de limitação relacionado a resultados captados por meio de pesquisas domiciliares, uma vez que as informações declaradas por meio de questionários podem ser tendenciosas, especialmente quando se trata de questões sobre a renda. A tendência geral é de não se revelar as rendas integralmente. Para Barros, Cury e Ulyssea (2007), estas restrições decorrem da dificuldade de se captar corretamente algumas fontes de renda, especialmente a renda não monetária dos pequenos agricultores, rendimentos de ativos e as rendas mais voláteis e eventuais.

As parcelas de rendimento que compõem a classe de assalariados (empregados) correspondem a mais de $50 \%$ da renda total declarada. Na relação de variáveis das PNAD 2001 e 2013, os empregados compreendem diversas categorias agregadas na variável identificada pelo código V4756 e V4706, respectivamente, como: empregados com carteira de trabalho assinada, militar, funcionários públicos estatutários, outros 
empregados sem carteira de trabalho assinada, empregados sem declaração de carteira de trabalho assinada, trabalhadores domésticos com carteira de trabalho assinada e trabalhadores domésticos sem carteira de trabalho assinada. A escolha pela análise dos dados relacionados aos anos 2001 e 2013 se deu pelo fato de o período compreender os anos iniciais do século XXI, com os dados disponibilizados pelo IBGE.

Diante de tal situação, neste trabalho, analisa-se a distribuição de rendimentos entre os empregados do setor público e privado, relacionado ao nível de escolaridade, nos anos de 2001 e 2013, da economia brasileira. A análise toma por base a participação dos empregados nessas atividades no rendimento total dos domicílios, em diferentes fontes de renda domiciliar per capita, pela decomposição do Índice de Gini, bem como a relação escolaridade e rendimento por gênero para os empregados.

Para alcançar este objetivo, na próxima seção, será realizada uma revisão de literatura; em seguida será apresentada a metodologia do trabalho, que informa a base de dados e a decomposição do Índice de Gini; na seção seguinte, apresenta-se a análise dos dados, com base nas PNAD de 2001 e 2013, que expõe a decomposição do índice geral de Gini, bem como a decomposição do Índice de Gini por grupamento de atividades, discutindo-se a influência da escolaridade na distribuição de renda; por último, apresentam-se as considerações finais com base nas análises desenvolvidas ao longo do artigo.

\section{REVISÃO DE LITERATURA}

Essa seção apresenta uma revisão de literatura abordando o ponto de vista empírico de trabalhos, sobre o contexto histórico econômico e social, além de verificar o comportamento da distribuição de renda e sua relação com a escolaridade no Brasil.

Em longo prazo, a difusão do conhecimento e a disseminação da educação de qualidade são fatores que de fato impulsionam o aumento da igualdade. Para Piketty (2014), o processo de difusão de conhecimento e competências é o principal instrumento para aumentar a produtividade. Ao mesmo tempo, a difusão do conhecimento contribui para reduzir a desigualdade, tanto dentro de um país quanto entre diferentes países. Ele acrescenta, também, que a falta de investimento adequado na capacitação de mão de obra pode excluir grupos sociais inteiros, levando-os a não desfrutarem dos benefícios do crescimento econômico ou, até mesmo, rebaixando-os em benefício de novos grupos sociais.

No Brasil, a desigualdade existe desde o período colonial. De acordo com Santana (2007), as atividades desenvolvidas posteriormente contribuíram para a manutenção dessa desigualdade. Exemplo disso foi o favorecimento da região Sudeste pela expor- 
tação de café, no século XIX. Em consequência do acúmulo de capital, esta região tornou-se o centro de produção industrial, e exportadora do país no início da industrialização, sendo a região com maior participação no Produto Interno Bruto.

Salvato, Ferreira e Duarte (2010) investigaram o impacto da escolaridade sobre a distribuição de renda do trabalho de estados e regiões do Brasil, tendo como base a tese de que a renda per capita baixa está relacionada com o nível de escolaridade e capital físico. A renda obtida é reflexo do investimento na educação e no aprimoramento do trabalho. Como resultado, mostram que boa parte do diferencial de renda entre as regiões é explicado pelo diferencial do grau de escolaridade; quanto mais elevado o nível de renda considerado, maior é a contribuição da escolaridade para a diferença de renda, concluindo-se que a desigualdade de renda é maior na região nordeste, mais pobre.

Daré e Hoffmann (2012) analisaram a desigualdade da distribuição de renda no Brasil no período de 2002 a 2009, verificando a contribuição dos rendimentos do funcionalismo público, por meio da decomposição do Índice de Gini e, para tanto, separaram os rendimentos em várias parcelas e detectaram que as mudanças ocorridas nos rendimentos dos servidores estatutários federais e estaduais foram as que mais contribuíram para o aumento do Índice de Gini. De acordo com os autores, estas parcelas aumentaram suas regressividades tanto pela ampliação das participações na renda total quanto pelo aumento das respectivas razões de concentração.

Quanto à redução da desigualdade de distribuição de renda no Brasil pós 2000, há controvérsias quanto à importância da parcela relacionada às transferências sociais. Hoffmann (2006) estuda a contribuição das parcelas do rendimento per capita nas cinco regiões do Brasil, no período de 1997 a 2005, e constata que o Índice de Gini caiu de 0,598 para 0,566 no período analisado. $\mathrm{O}$ autor atribui essa redução tanto à parcela que inclui as transferências do governo, como por exemplo o Programa Bolsa Família, quanto ao rendimento de todos os trabalhos.

Soares (2006) analisa a distribuição de renda no Brasil dando ênfase ao período de 2001 e 2004, apontando o mercado de trabalho, e não os programas de transferência de renda do governo, como o principal responsável pela diminuição na desigualdade. Além disso, o autor argumenta que mudança na oferta ou demanda de trabalho pode ser sustentável, enquanto programas sociais de transferência não o são, exigindo do governo grande fatia do orçamento para mantê-los.

Em uma pesquisa posterior, dessa vez utilizando a Pesquisa de Orçamentos Familiares (POF) de 2002-2003 e 2008-2009, Hoffmann (2010) relata que realmente houve redução da desigualdade de renda, em que o Índice de Gini diminuiu de 0,591 para 0,561. A redução é observada em todas as regiões analisadas, sendo que a desigualdade 
é menor nas regiões mais desenvolvidas, como a região Sul e no estado de São Paulo. O autor constata também que a parcela do rendimento de aposentadorias e pensões de funcionários públicos é componente regressivo, diferentemente das transferências de programas sociais do governo, que são progressivas.

Para que haja mudanças no mercado de trabalho, é imprescindível investimentos no sistema educacional, como destaca Ramos (2007), quando fala sobre a importância da escolaridade como redutor da desigualdade de renda, observando que a melhora na distribuição de renda ocorre por mudanças na oferta e na demanda de qualificação no mercado de trabalho. Reforçando essa argumentação, Neri (2007) enfatiza que é necessário grande investimento na educação para reduzir a desigualdade e aumentar o crescimento econômico, reduzindo consequentemente, a pobreza.

Um relato bastante contundente é o estudo de Reis e Ramos (2011) que, analisando a relação entre a distribuição de rendimentos do trabalho no Brasil e a escolaridade dos pais dos trabalhadores, concluíram que a estrutura educacional familiar é um importante determinante da desigualdade nos rendimentos do trabalho.

Uma investigação dos determinantes do diferencial de rendimentos público-privado para diferentes níveis de escolaridade dos trabalhadores no Brasil desenvolvido por Braga, Firpo e Gonzaga (2009), tendo como base de dados da PNAD 2005, apresenta resultados diferentes para níveis de escolaridades diferentes. Os autores utilizaram o rendimento do trabalho principal como variável de interesse e estimaram um hiato de rendimentos bastante favorável para os trabalhadores com baixa escolaridade do setor público. Ao considerar os trabalhadores com maiores níveis de capital humano, o hiato praticamente desapareceu ou mesmo passou a ser favorável ao setor privado. Uma explicação para este fenômeno apresentada pelos autores diz respeito à existência de pisos e tetos salariais bem definidos no setor público.

Souza e Medeiros (2013) analisaram o diferencial salarial público-privado e desigualdade de renda no Brasil, com os dados da PNAD 2009, por meio de simulações contrafactuais e cálculo das contribuições para mensurar a desigualdade em uma decomposição do coeficiente de Gini. Concluíram que a massa salarial dos funcionários públicos é regressiva e altamente concentrada. Para os autores, os servidores públicos ganham em torno de um quinto a mais do que trabalhadores do setor privado. Essa diferença é justificada por dois fatores: o efeito composição, em que o maior nível educacional da força de trabalho do setor público explica o recebimento de salários maiores que os trabalhadores de menor qualificação; e o efeito segmentação, em que a existência de um diferencial salarial favorável aos trabalhadores públicos reflete diferenças nas regras de determinação de salários para trabalhadores com características semelhantes. 
Para Daré e Hoffmann (2013), a influência dos rendimentos do setor público na desigualdade da distribuição da renda mudou ao longo do tempo. Os autores analisam a contribuição da parcela de renda do funcionalismo público na distribuição da renda no Brasil no período de 1995 a 2009, utilizando os dados da PNAD deste período e, por meio da decomposição do Índice de Gini, realizaram a investigação considerando tanto o número de funcionários quanto seus rendimentos. Concluíram que, de 1995 a 2002, os rendimentos do setor público contribuíram para a queda do Índice de Gini, mas, no período seguinte, de 2003 a 2009, colaboraram para o aumento da desigualdade da renda.

Brasil (2016) analisou o hiato de rendimentos público-privado no Brasil no período de 2004 a 2013, por meio da Decomposição de Oaxaca-Blinder, Regressão Quantílica e Decomposição Quantílica de Melly. Detectou que há um diferencial em favor dos trabalhadores do setor público em todo o período analisado e em todas as regiões do país. O hiato apresentou relativa estabilidade durante o período. Para o autor, três quartos do diferencial são devidos a atributos produtivos e o restante está relacionado à diferença setorial entre os grupos.

Para tratar do diferencial dos rendimentos em decorrência do gênero, Freisleben e Bezerra (2012) analisam a diferença salarial por gênero entre homens e mulheres na região Sul do Brasil, com as informações da PNAD de 1998 e 2008, utilizando o método da decomposição de Oaxaca-Blinder. Apontaram que, apesar de as mulheres estarem mais escolarizadas, ainda existe diferencial salarial em favor dos homens, não explicado pela diferença de atributos, indicando a existência de discriminação no mercado de trabalho na área estudada. Andrade (2016) apresenta resultados semelhantes, ao traçar um panorama da participação das mulheres no mercado de trabalho, enfocando a desigualdade de rendimentos entre homens e mulheres. A autora analisa o período de 2004 a 2014, com dados do IBGE. Conclui que as mulheres recebem menos do que os homens, mesmo tendo escolaridade mais elevada e que, no período analisado, ocorreu redução nas desigualdades salariais entre homens e mulheres. Para a autora, a valorização do salário mínimo parece ter exercido um importante papel nesse processo.

\section{METODOLOGIA}

\subsection{INFORMAÇÕES SOBRE A BASE DE DADOS}

A principal fonte de informações para este estudo é a base de dados disponibilizada pelo IBGE: os microdados da Pesquisa Nacional por Amostra de Domicílios (PNAD) do ano de 2001 e de 2013. A PNAD é uma pesquisa domiciliar com representatividade nacional. 
O IBGE realiza um levantamento anual por meio de uma amostra dos domicílios que alcançam todo o território nacional. Até 2003, a pesquisa não abrangia a área rural dos estados da região Norte (Acre, Amapá, Amazonas, Pará, Rondônia e Roraima). Como este trabalho utiliza os dados de 2001 e 2013, esta área rural será desconsiderada da PNAD de 2013, para evitar incoerência nas comparações.

Para o cálculo da decomposição do Índice de Gini, utiliza-se o rendimento domiciliar per capita (RDPC), que é a razão entre o rendimento domiciliar e o número de moradores. Considera-se a declaração do rendimento domiciliar apenas dos domicílios particulares permanentes. Também são excluídos da condição de unidade domiciliar os pensionistas, empregados domésticos e os parentes dos empregados domésticos.

Como empregado, será considerada (código de variável V4756-2001 e V47062013) a pessoa que trabalha para um empregador (seja o empregador pessoa física ou jurídica) e que, em contrapartida ao cumprimento do trabalho prestado, recebe uma remuneração. Sendo assim, será considerado empregado o trabalhador doméstico que presta serviço doméstico remunerado em dinheiro ou benefícios; não será considerado empregado o trabalhador não remunerado, o trabalhador para o próprio consumo, o trabalhador por conta própria e o empregador.

O IBGE adota um procedimento metodológico em que cada pessoa da amostra representa um determinado número de pessoas da população. Para os dados individuais são fornecidos o peso ou fator de expansão de cada indivíduo, permitindo que os cálculos sejam efetuados com cada observação e expandidos para a população por meio da ponderação do seu respectivo peso. Neste trabalho, os cálculos serão executados com o peso de cada observação da amostra fornecido pelo IBGE.

\subsection{DECOMPOSIÇÃO DO ÍNDICE DE GINI}

Com o cálculo da decomposição do Índice de Gini, é possível verificar a contribuição de cada componente da renda da população. Ou seja, este método de análise examina a influência de cada componente para a desigualdade total e analisa como esses componentes contribuem para aumentar ou reduzir a concentração dos rendimentos.

Este trabalho seguirá a mesma metodologia utilizada por Hoffmann (2009) e Pyatt, Chen e Fei (1980), a qual considera $x_{i}$ o rendimento domiciliar per capita de cada residente. É sabido que um indivíduo pode ter sua renda originária de várias fontes, então a renda domiciliar per capita da i-ésima pessoa será o somatório das parcelas.

Para o cálculo de Índice de Gini, é necessário que as rendas $x_{i}$ estejam ordenadas de maneira que $x_{1} \leq x_{2} \leq \ldots x_{n}$, sendo $n$ o tamanho da população pesquisada e, $i$ a posição de ordem da renda domiciliar per capita de cada indivíduo. 
Nestas circunstâncias, o ponto de partida para calcular o Índice de Gini é:

$$
G=\frac{2}{n \mu} \operatorname{cov}\left(i, x_{i}\right)
$$

Considerando que $x_{i}$ é o somatório de $k$ parcelas e $x_{h i}$ as respectivas parcelas, de maneira que

$$
x_{i}=\sum_{h=1}^{k} x_{h i}
$$

Sendo $\mu$ a renda média da população pesquisada, dada por

$$
\mu=\frac{1}{n} \sum_{i=1}^{n} x_{i}
$$

Para calcular a renda média de uma parcela específica, segue-se o mesmo critério, ou seja

$$
\mu_{h}=\frac{1}{n} \sum_{i=1}^{n} x_{h i}
$$

Percebe-se nessa expressão que o $n$ da média da parcela é exatamente o mesmo da média da população, ou seja, o tamanho da população.

A razão de concentração da h-ésima parcela é calculada da seguinte maneira:

$$
C_{h}=\frac{2}{n \mu_{h}} \operatorname{cov}\left(i, x_{h i}\right)
$$

Em (5), $\mu_{h}$ é a média dos rendimentos da h-ésima parcela.

Uma observação importante é feita por Rossi (1983) em que $C_{h}$ é o índice de concentração para a parcela $h$ quando os dados são ordenados segundo os níveis da renda total e, portanto, não deve ser confundido com o Índice de Gini para aquela parcela, que requer a ordenação das rendas por níveis crescentes das rendas da parcela.

A participação da h-ésima parcela na renda total pode ser obtida pelo quociente de sua renda média em relação à renda média total, ou seja,

$$
\varphi_{h}=\frac{\sum_{i=1}^{n} x_{h i}}{\sum_{i=1}^{n} x_{i}} \Rightarrow \varphi_{h}=\frac{\mu_{h}}{\mu}
$$


Considerando que o Índice de Gini é uma média das razões de concentrações ponderada pela proporção da participação das parcelas na renda total, ou pela proporção da renda média da h-ésima parcela em relação à renda média da população, ou seja, da equação (1), (5) e (6), pode-se deduzir que

$$
G=\sum_{h=1}^{k} \varphi_{h} C_{h}
$$

Para Pyatt, Chen e Fei (1980), o coeficiente de Gini pode ser expresso como a média ponderada das razões de concentração de todas as parcelas de rendas em relação ao total dos rendimentos. Por meio da equação (7), é possível definir o conceito de regressividade e progressividade, em que é determinado se uma fonte de renda é regressiva ou progressiva no cálculo do Índice de Gini. Percebe-se que, se as razões de concentração $C_{h}$ de todas as parcelas apresentarem o mesmo valor, esse seria o valor de $G$, ou seja, a razão de concentração de uma h-ésima parcela não estaria influenciando na desigualdade de rendas, nem para mais nem para menos.

Sendo assim, é ponderável considerar a diferença entre o Índice de Gini e a razão de concentração como Medida de Progressividade $\left(\pi_{h}\right)$. Esta medida é definida por Lerman e Yitzhaki (1985, apud Hoffmann, 2009) como:

$$
\pi_{h}=G-C_{h}
$$

Assim, quando $\pi_{h}$ for positivo, isto implica que a razão de concentração $C_{h}$ dessa parcela é menor que o Índice de Gini $\left(C_{h}<G\right)$, então esta parcela será considerada progressiva, pois contribui para reduzir a desigualdade de distribuição de renda. A parcela será regressiva quando o $\pi_{h}$ for negativo: a razão de concentração da parcela estará acima do Índice de Gini $\left(C_{h}>G\right)$, indicando que esta parcela coopera para aumentar a desigualdade.

\section{ANÁLISE DOS DADOS}

Nesta seção, analisa-se inicialmente a decomposição do Índice de Gini em diversas fontes de rendas, e se permite verificar a participação de cada fonte de renda na renda total e a contribuição de cada fonte de renda na composição do Índice de Gini. A partir de então, será analisada a distribuição de rendas dos empregados.

Comumente a renda domiciliar per capita é utilizada na obtenção de medidas de desigualdade de rendas por ser uma variável de indicação do nível de vida de uma 
pessoa. Para a decomposição do Índice de Gini da distribuição do rendimento domiciliar per capita no Brasil em 2001 e 2013, mostrado na Tabela 1, segue-se a base metodológica apresentada na seção 3.

As informações de cada fonte de renda são mutuamente exclusivas do rendimento domiciliar. O primeiro subtotal, "A-Empregados do setor público", compreende os rendimentos de todos os empregados do setor público que agrega as categorias de militares e os funcionários públicos estatutários; o segundo subtotal, "B-Empregados do setor privado", se refere aos empregados do setor privado com e sem carteira assinada e, também, aos domésticos com e sem carteira assinada; o subtotal "C" refere-se ao somatório dos rendimentos dos empregados, tanto do setor público quanto do setor privado. Em seguida, o subtotal "D-Outras" rendas do trabalho relaciona o rendimento de quem trabalha por conta própria e dos empregadores; o subtotal "E-Total de rendas do trabalho" considera todas as rendas do trabalho, tanto para empregados quanto para trabalhadores por conta própria e empregadores. Por último, o subtotal F refere-se aos rendimentos não oriundos de trabalho (agregando aposentadorias, pensões, abonos e doações, rendas de aluguel e juros).

Considerando o conceito de progressividade e regressividade, o rendimento dos empregados em 2001 e 2013 apresentou o mesmo resultado, sendo que a progressividade em 2001 era mais acentuada e a diferença entre o $\left(G-C_{h}\right)$ passou de 0,035 para 0,005. Em 2013, a participação do rendimento dos empregados $(53,1 \%)$ é praticamente igual a sua participação na composição do Índice de Gini (52,6\%), fazendo com que este rendimento seja levemente progressivo, sem significância quanto a sua progressividade; porém, analisando separadamente, o rendimento do setor público (militar e funcionários públicos estatutários) é bastante regressivo, ou seja, este rendimento agrava a distribuição de rendas no Brasil. Em contrapartida, o rendimento do setor privado é progressivo, sendo assim, este rendimento contribui para diminuir a desigualdade de rendas medida pelo Índice de Gini.

Este resultado é compatível com os apresentados por Souza e Medeiros (2013) que, ao analisar o ano de 2009, detectaram que a massa salarial do setor público é regressiva. Já Daré e Hoffmann (2013), utilizando a mesma metodologia, apresentam resultados semelhantes apenas para o período de 2003 a 2009, em que os rendimentos do setor público contribuíram para aumentar a desigualdade da distribuição de renda.

O rendimento do trabalho, em 2013, representa 74,0\% da renda total, menor do que sua participação na composição do Índice de Gini: 77,4\%. Assim, este rendimento é regressivo e a renda dos empregadores é a principal responsável por isto, já que é a parcela de renda mais regressiva dentre as analisadas. Em 2001, a análise é similar, com o rendimento da parcela conta própria sendo progressiva e a renda dos empregadores regressiva. Porém, somado o rendimento dos empregados, a renda de todo o trabalho 
apresenta-se levemente progressiva. Esta situação muda em 2013, passando a ser regressiva, impulsionada pela regressividade do funcionalismo público.

Pode-se deduzir, com base nos números apresentados, que, no período analisado, de 2001 a 2013, o rendimento dos funcionários públicos passou a ter uma influência maior na composição do Índice de Gini, de 12,7\% para 15,9\%, e, seu caráter de uma fonte de renda regressiva intensificou-se ainda mais.

\section{Tabela 1 - Decomposição do índice de Gini por fontes de renda domiciliar per capita, Brasil (2001 e 2013)}

\begin{tabular}{|c|c|c|c|c|c|c|c|c|}
\hline \multirow{2}{*}{ Descrição } & \multicolumn{4}{|c|}{2001} & \multicolumn{4}{|c|}{2013} \\
\hline & $\phi_{\mathrm{h}}$ & $\mathrm{C}_{\mathrm{h}}$ & $\%$ & $\pi_{\mathrm{h}}$ & $\phi_{\mathrm{h}}$ & $\mathrm{C}_{\mathrm{h}}$ & $\%$ & $\pi_{h}$ \\
\hline Militar & 0,0060 & 0,7224 & 0,76 & $-0,151$ & 0,0043 & 0,6508 & 0,55 & $-0,145$ \\
\hline Funcionário Público & 0,0937 & 0,7308 & 11,98 & $-0,159$ & 0,1039 & 0,7477 & 15,37 & $-0,242$ \\
\hline A-Empregados Setor Público & 0,0997 & 0,7303 & 12,74 & $-0,159$ & 0,1082 & 0,7438 & 15,92 & $-0,238$ \\
\hline Empregado com Cart. Assinada & 0,2615 & 0,5601 & 25,63 & 0,011 & 0,3039 & 0,4829 & 29,03 & 0,023 \\
\hline Empregado sem Cart. Assinada & 0,1185 & 0,4318 & 8,95 & 0,140 & 0,0928 & 0,3932 & 7,22 & 0,112 \\
\hline E. Doméstico com Cart. Assinada & 0,0087 & 0,1707 & 0,26 & 0,401 & 0,0106 & 0,1741 & 0,37 & 0,331 \\
\hline E. Doméstico sem Cart. Assinada & 0,0200 & 0,0458 & 0,16 & 0,526 & 0,0156 & 0,0064 & 0,02 & 0,499 \\
\hline B-Empregados Setor Privado & 0,4087 & 0,4894 & 35,00 & 0,082 & 0,4229 & 0,4379 & 36,63 & 0,068 \\
\hline C-Total Empregados & 0,5084 & 0,5367 & 47,74 & 0,035 & 0,5311 & 0,5003 & 52,55 & 0,005 \\
\hline Conta Própria & 0,1475 & 0,4982 & 12,86 & 0,073 & 0,1373 & 0,4758 & 12,92 & 0,030 \\
\hline Empregador & 0,0889 & 0,8464 & 13,17 & $-0,275$ & 0,0711 & 0,8493 & 11,94 & $-0,344$ \\
\hline D-Outras Rendas do Trabalho & 0,2364 & 0,6292 & 26,02 & $-0,058$ & 0,2084 & 0,6032 & 24,87 & $-0,098$ \\
\hline E-Total Rendas do Trabalho & 0,7448 & 0,5660 & 73,76 & 0,006 & 0,7395 & 0,5293 & 77,42 & $-0,024$ \\
\hline Aposentadoria e Pensões & 0,1932 & 0,5839 & 19,74 & $-0,012$ & 0,2024 & 0,5105 & 20,44 & $-0,005$ \\
\hline Outras Aposentadorias/Pensões & 0,0191 & 0,6033 & 2,02 & $-0,032$ & 0,0145 & 0,4720 & 1,35 & 0,034 \\
\hline Abono e Doações & 0,0105 & 0,4477 & 0,82 & 0,124 & 0,0042 & 0,3598 & 0,30 & 0,146 \\
\hline Aluguéis & 0,0177 & 0,7612 & 2,36 & $-0,190$ & 0,0113 & 0,7597 & 1,70 & $-0,254$ \\
\hline Juros, transferências e outros & 0,0147 & 0,5059 & 1,30 & 0,066 & 0,0281 & $-0,2176$ & $-1,21$ & 0,723 \\
\hline F-Outras Rendas & 0,2552 & 0,5876 & 26,24 & $-0,016$ & 0,2605 & 0,4382 & 22,58 & 0,067 \\
\hline Total & 1,0000 & 0,5715 & 100,00 & & 1,0000 & 0,5055 & 100,00 & \\
\hline
\end{tabular}

Fonte: Elaboração própria com base em dados da PNAD/IBGE de 2001 e 2013.

Com relação às fontes de rendas que não têm como origem o trabalho, a mais significativa é o rendimento de aposentadorias e pensões que tem uma participação em torno de 20,0\% do rendimento total nos dois anos analisados. Este rendimento apresenta pequena diferença $\left(G-C_{h}\right)$, indicando ser pouco regressivo, uma vez que reúne 
rendimentos claramente progressivos, como aposentadorias e pensões do setor privado, juntamente com outros, que são regressivos, como aposentadorias e pensões de ex-funcionários públicos. Ferreira e Souza (2008), analisando aposentadorias e pensões no meio urbano e rural do Brasil, concluíram que este rendimento contribui para aumentar a concentração de renda no país.

Entre as parcelas analisadas, os rendimentos mais regressivos são os dos empregadores e funcionários públicos estatutários que juntos representam mais $25 \%$ da composição do Índice de Gini, tanto em 2001 quanto em 2013. O rendimento de aluguéis também é bastante regressivo, porém tem pouca representatividade na renda total e na composição do Índice de Gini.

De 2001 a 2013, a parcela que sofreu maior mudança foi o rendimento de juros e transferências (juros de caderneta de poupança e outras aplicações financeiras, dividendos e outros rendimentos, como transferências de programas sociais), mas é uma fonte de renda com pouca participação na renda total e também na composição do Índice de Gini. Boa parte da mudança pode ser explicada por programas sociais implementados no período. Daré e Hoffmann (2012), analisando a desigualdade da distribuição de renda da economia brasileira no período de 2002 a 2009, englobam, em uma mesma parcela de renda, doações, aluguéis, juros, programas sociais e outros rendimentos. Afirmam que esta parcela, que era regressiva em 2002, se converte em progressiva em 2009 e a principal justificativa dos autores foi a expansão do Programa Bolsa Família no período.

Para a decomposição do Índice de Gini, os setores público e privado foram desdobrados em diferentes parcelas, sendo o primeiro em duas: militar e funcionário público estatutário; e o segundo, em quatro parcelas de rendimento: empregado com e sem carteira assinada e trabalhador doméstico com e sem carteira assinada. Assim, fica evidenciado que o rendimento do setor público é regressivo, e o do setor privado, progressivo.

No setor público, $96 \%$ do rendimento total referem-se aos funcionários públicos estatutários, os militares representam $4 \%$ das rendas totais. Ambos apresentam a razão de concentração maior que o Índice de Gini: 0,572 e 0,506 em 2001 e 2013, respectivamente, confirmando que estas parcelas de renda são regressivas e contribuem para aumentar a concentração de rendas, que, em outras palavras, impelem o Índice de Gini para cima.

As parcelas de rendimento que representam o setor privado são progressivas e têm uma participação significativa de 40,9\% e 42,3\% do rendimento total, e uma menor contribuição para o Índice de Gini de 35,0\% e 36,6\%, respectivamente. A fonte de renda com maior participação no rendimento entre os empregados do setor privado é a parcela referente aos empregados com carteira assinada de 64,0\% em 2001 e que aumentou para $71,8 \%$ em 2013, enquanto a parcela dos empregados sem carteira assinada sofreu queda de $29,0 \%$ para $22,0 \%$ no período. Isto demonstra uma mudança na classe operária, que passou a usufruir dos direitos constitucionais de maior garantia do emprego e a contribuir com a previdência social. 
No que diz respeito aos trabalhadores domésticos, estes apresentam a menor participação relativa ao rendimento do trabalhador privado. No período analisado, ocorreu uma mudança idêntica a dos empregados, ou seja, houve um aumento na participação do rendimento do trabalhador doméstico com carteira assinada e redução do trabalhador sem carteira assinada. No entanto, estas duas parcelas de rendimento são as que mais contribuem para reduzir a concentração de renda, nos dois anos da análise, ainda que a influência seja pequena, uma vez que, juntas, contribuem com pouco mais de $1 \%$ da composição do Índice de Gini do setor privado.

Todas as parcelas de rendimento do setor privado apresentam razão de concentração menor do que o Índice de Gini, contribuindo para melhorar a distribuição de rendas do país. Juntando empregado sem carteira assinada e trabalhador doméstico sem carteira assinada, tem-se $34, \%$ e $25,7 \%$ do rendimento do setor privado, ou seja, em 2001 mais um terço (1/3), e em 2013, houve uma redução no percentual, mas ainda permanece bastante alto, em que mais de um quarto (1/4) dos empregados do setor privado não têm carteira de trabalho assinada, portanto não têm todos os direitos constitucionais garantidos.

A Curva de Lorenz facilita a visualização desta análise. O Gráfico 1 plota o rendimento dos setores público e privado, que exibe a diferença do Índice de Gini de 0,545 e 0,482 para os anos de 2001 e 2013, respectivamente.

\section{Gráfico 1 - Curva de Lorenz da distribuição da renda domiciliar per capita - rendimentos dos empregados, Brasil (2001 e 2013)}

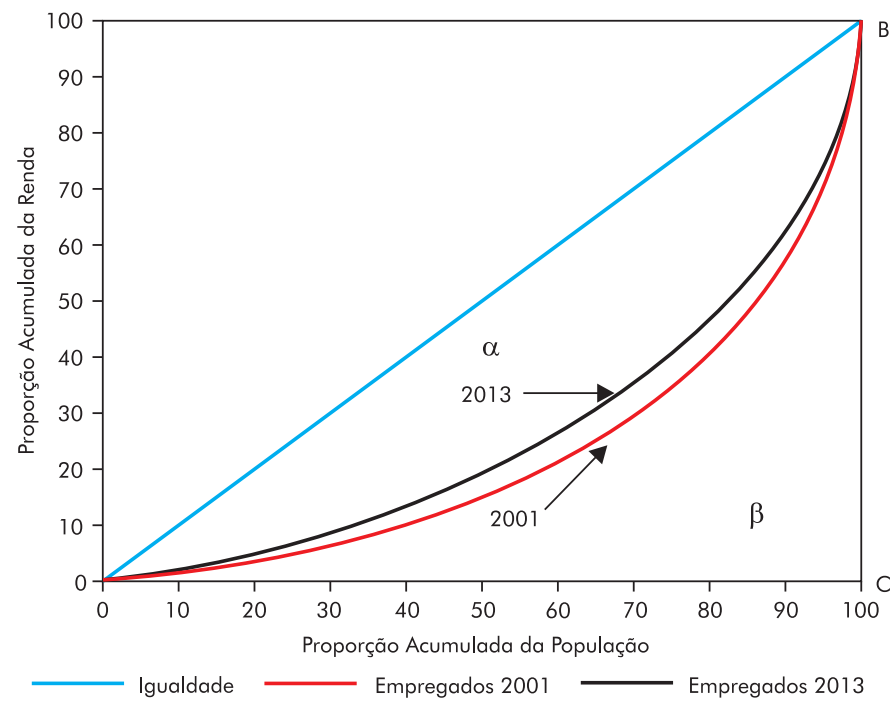


Percebe-se que a Curva de Lorenz da distribuição da renda referente ao ano de 2013 está mais próxima da linha de perfeita igualdade do que a curva que representa a distribuição do ano 2001 e, por conseguinte, os valores da área $\alpha$ para a distribuição dos rendimentos em 2001 são maiores do que para os rendimentos de 2013. Consequentemente, o Índice de Gini para a distribuição da renda dos empregados daquele ano também é maior do que para os empregados deste ano.

A Tabela 2 mostra a decomposição do Índice de Gini do rendimento dos empregados (setor público e setor privado). O critério de elaboração desta tabela seguiu a mesma metodologia da decomposição do índice total, diferenciando-se no fato de que, aqui, se considera apenas o rendimento dos empregados. Para comparar 2001 com 2013, foi necessário juntar outros serviços coletivos, sociais e pessoais e atividades mal definidas em um único grupamento de atividades, em 2013.

Os grupamentos de atividades com maiores participações no rendimento total dos empregados são: educação, saúde e serviços sociais; administração pública; comércio e reparação; e indústria de transformação. Destes, os dois primeiros são regressivos e os dois últimos são progressivos e isto é condizente com os dados apresentados na Tabela 1, em que se mostrou o rendimento do setor público regressivo e do setor privado progressivo. Os dois grupamentos de atividades (educação, saúde e serviços sociais; administração pública) tratam, basicamente, de empregados do setor público. $\mathrm{E}$ os grupamentos de atividades (comércio e reparação; e indústria de transformação) referem-se inerentemente a empregados do setor privado.

\section{Tabela 2 - Decomposição do Índice de Gini do rendimento dos empregados por grupamento de atividades, considerando rendimento domiciliar per capita, Brasil (2001 e 2013)}

\begin{tabular}{|c|c|c|c|c|c|c|c|c|}
\hline Descrição & \multicolumn{4}{|c|}{2001} & \multicolumn{4}{|c|}{2013} \\
\hline Outras atividades industriais & 0,0177 & 0,5594 & 1,82 & $-0,014$ & 0,0155 & 0,6528 & 2,10 & $-0,171$ \\
\hline Indústria de transformação & 0,1378 & 0,4750 & 12,00 & 0,070 & 0,1216 & 0,4061 & 10,24 & 0,076 \\
\hline Comércio e reparação & 0,1214 & 0,5052 & 11,24 & 0,040 & 0,1377 & 0,3368 & 9,62 & 0,145 \\
\hline Alojamento e alimentação & 0,1368 & 0,2618 & 6,57 & 0,284 & 0,0293 & 0,2065 & 1,26 & 0,276 \\
\hline Transporte, armazenagem e comunicação & 0,0464 & 0,5293 & 4,50 & 0,016 & 0,0521 & 0,3847 & 4,16 & 0,097 \\
\hline Serviços domésticos & 0,0668 & 0,7068 & 8,66 & $-0,161$ & 0,0493 & 0,0059 & 0,06 & 0,476 \\
\hline \multirow[t]{2}{*}{$\begin{array}{l}\text { Outras atividades, atividades mal definidas } \\
\text { ou não declaradas }\end{array}$} & 0,0451 & 0,8042 & 6,65 & $-0,259$ & 0,1606 & 0,5981 & 19,92 & $-0,116$ \\
\hline & 1,000 & 0,545 & 100,00 & & 1,000 & 0,482 & 100,00 & \\
\hline
\end{tabular}


Entre os grupamentos de atividades analisados, o rendimento da administração pública é o que apresenta a maior regressividade, enquanto os grupamentos relacionados às atividades agrícolas e serviços domésticos são os mais progressivas ao Índice de Gini dos empregados. Estes resultados também confirmam os resultados obtidos na Tabela 1.

A diferença na progressividade dos setores público e privado pode ser explicada, em parte, pelo rendimento médio pago por cada setor e o nível de escolaridade dos empregados de cada setor. A Tabela 3 mostra o rendimento médio dos setores público e privado separado por nível de instrução dos empregados. Percebe-se que o setor público tem uma remuneração média de quase o dobro do setor privado, 97,4\%. Em alguns níveis, a diferença é bem significativa, como os empregados classificados sem grau de instrução, com remuneração equivalente a 76,2\% (supõe-se que sejam antigos funcionários do setor público, que ingressaram no trabalho, quando não havia exigência de concurso público). Os níveis de instrução fundamental completo e médio completo também apresentam alto percentual de diferença na remuneração $(32,3 \%$ e $31,5 \%$, respectivamente): o setor público paga quase um terço (1/3) a mais do que o setor privado, pois são níveis de instrução exigidos em alguns concursos para o ingresso no serviço público.

A renda média total (última coluna de valores na Tabela 3) não é uma média entre os empregados, mas refere-se à média total da economia, incluindo o rendimento de todos os trabalhos e transferências. Por isso, no nível superior completo, o rendimento médio total de $\mathrm{R} \$ 3.088,72$ é maior do que a renda média dos empregados (setor público e setor privado), por incluir pessoas com nível superior completo que trabalham por conta própria e os empregadores.

Tabela 3 - Rendimento médio por nível de instrução - setor público e setor privado, Brasil (2013)

\begin{tabular}{lcccc}
\hline \multirow{2}{*}{ Nível de Instrução } & \multicolumn{2}{c}{ Renda Média } & \% Públ./Priv. & $\begin{array}{c}\text { Renda Med. } \\
\text { Total }\left(^{*}\right)\end{array}$ \\
\cline { 2 - 3 } & S. Público & S. Privado & & 619,40 \\
\hline Sem instrução & $1.004,34$ & 570,13 & 76,2 & 695,38 \\
Fundamental incompleto & 740,00 & 620,52 & 19,3 & 832,50 \\
Fundamental completo & 968,03 & 730,59 & 32,5 & 743,52 \\
Médio incompleto & 875,38 & 714,04 & 22,6 & $1.069,34$ \\
Médio completo & $1.231,82$ & 935,98 & 31,6 & $1.620,43$ \\
Superior incompleto & $1.691,87$ & $1.483,48$ & 14,0 & $3.088,72$ \\
Superior completo & $2.911,35$ & $2.694,20$ & 8,1 & $\mathbf{1 . 1 3 3 , 6 4}$ \\
Média Ponderada & $\mathbf{2 . 0 3 0 , 6 4}$ & $\mathbf{1 . 0 2 8 , 8 9}$ & $\mathbf{9 7 , 4}$ & \\
\hline
\end{tabular}

Nota: (*) Média total da economia (todos os rendimentos)

Fonte: Elaboração própria com base em dados da PNAD/IBGE de 2013. 
O Gráfico 2 expõe que quase a metade dos funcionários públicos são portadores de diploma de curso superior, enquanto no setor privado apenas $11 \%$ dos empregados têm o superior completo. Os empregados com baixa escolaridade, até o nível médio incompleto, aparecem em maior proporção no setor privado e, somando os quatro níveis iniciais, têm-se 47,8\% de empregados do setor privado contra $13,2 \%$ do setor público. Essa diferença na alocação dos empregados dos setores público e privado, com os empregados do setor público ocupando posição com nível de instrução mais elevado e, consequentemente, salários mais elevados, faz com que a renda média ponderada do setor público seja quase o dobro que a do setor privado.

No nível médio completo, encontra-se o maior percentual dos empregados do setor privado $34,5 \%$, refletindo as dificuldades de acesso em um curso superior, porque muitos estudantes param de estudar para se dedicar ao trabalho.

No setor público, os maiores percentuais de frequência de funcionários são no nível superior completo e nível médio completo, por serem os dois principais níveis de instrução requeridos em diversos concursos públicos.

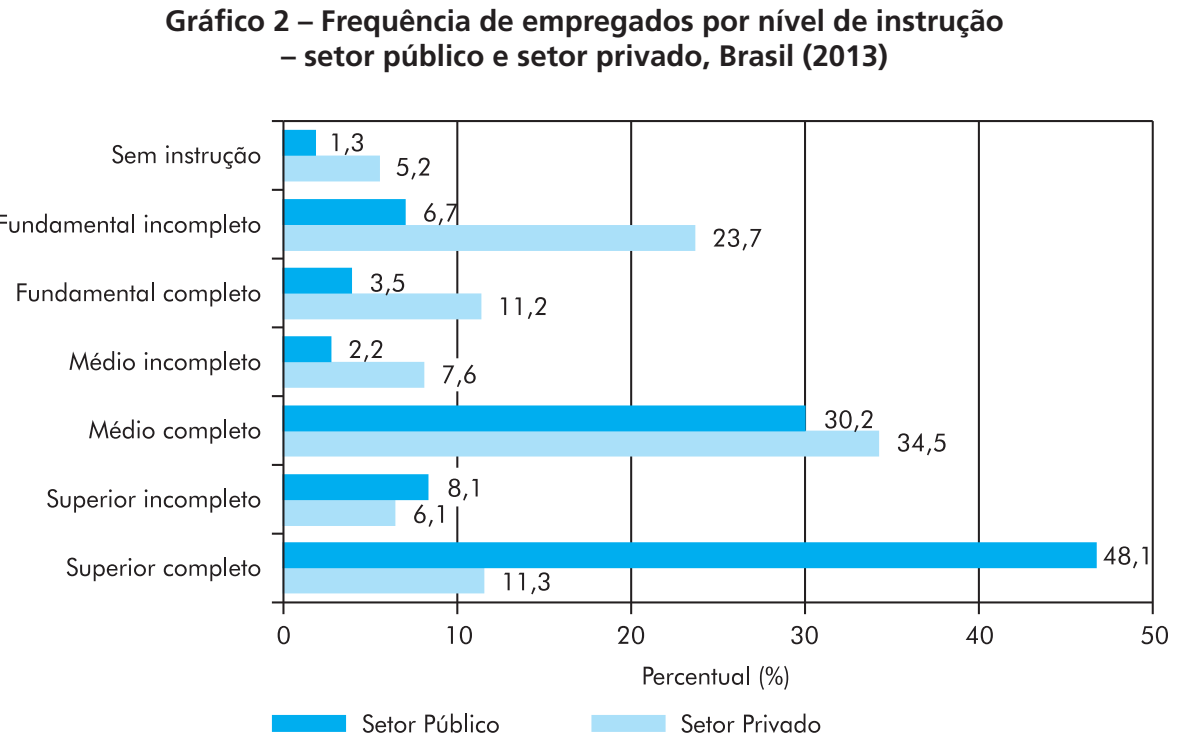

Fonte: Elaboração própria com base em dados da PNAD/IBGE de 2013.

Um dos fatores usado por Souza e Medeiros (2013) para explicar a diferença salarial nos dois setores é o efeito composição, em que os funcionários do setor público possuem maior nível educacional, por isto recebem salários maiores que os trabalhadores de menor qualificação. 
Analisando o rendimento domiciliar per capita dos empregados e do total, relacionando os anos de estudo para cada faixa salarial, conforme apresentado na Tabela 4, percebe-se, em todas as situações nos dois anos analisados, que quem estudou mais detém maiores faixas salariais.

Tabela 4 - Frequência de empregados por faixa salarial do rendimento per capita e anos de estudo, Brasil (2001 e 2013)

\begin{tabular}{|c|c|c|c|c|c|c|c|c|}
\hline \multirow{3}{*}{ Faixa Salarial } & \multicolumn{4}{|c|}{2001} & \multicolumn{4}{|c|}{2013} \\
\hline & \multicolumn{2}{|c|}{ Setor Público } & \multicolumn{2}{|c|}{ Setor Privado } & \multicolumn{2}{|c|}{ Setor Público } & \multicolumn{2}{|c|}{ Setor Privado } \\
\hline & $\begin{array}{c}\text { Frequência } \\
\%\end{array}$ & $\begin{array}{l}\text { Anos de } \\
\text { Estudo }\end{array}$ & $\begin{array}{c}\text { Frequência } \\
\%\end{array}$ & $\begin{array}{c}\text { Anos de } \\
\text { Estudo }\end{array}$ & $\begin{array}{c}\text { Frequência } \\
\%\end{array}$ & $\begin{array}{l}\text { Anos de } \\
\text { Estudo }\end{array}$ & $\begin{array}{c}\text { Frequência } \\
\%\end{array}$ & $\begin{array}{c}\text { Anos de } \\
\text { Estudo }\end{array}$ \\
\hline $\begin{array}{l}\text { Até } 1 / 4 \text { salário } \\
\text { mínimo }\end{array}$ & 0,94 & 5,8 & 5,11 & 4,3 & 0,50 & 9,5 & 3,11 & 6,5 \\
\hline $\begin{array}{l}\text { Mais de } 1 / 4 \text { até } 1 / 2 \\
\text { SM }\end{array}$ & 4,28 & 7,3 & 13,12 & 5,5 & 5,10 & 10,3 & 13,52 & 7,9 \\
\hline $\begin{array}{l}\text { Mais de } 1 / 2 \text { até } 1 \\
\text { SM }\end{array}$ & 13,12 & 9,2 & 26,35 & 6,9 & 17,05 & 11,6 & 31,76 & 9,2 \\
\hline $\begin{array}{l}\text { Mais de } 1 \text { até } 2 \\
\text { SM }\end{array}$ & 24,80 & 10,8 & 28,59 & 8,4 & 30,60 & 13,0 & 33,48 & 10,4 \\
\hline $\begin{array}{l}\text { Mais de } 2 \text { até } 3 \\
\text { SM }\end{array}$ & 17,54 & 12,1 & 11,09 & 10,0 & 16,10 & 14,0 & 9,42 & 12,1 \\
\hline $\begin{array}{l}\text { Mais de } 3 \text { até } 5 \\
\text { SM }\end{array}$ & 18,27 & 13,3 & 8,36 & 11,3 & 15,72 & 14,8 & 5,07 & 13,4 \\
\hline Mais de 5 SM & 21,05 & 14,7 & 7,38 & 13,3 & 14,92 & 15,4 & 3,64 & 14,8 \\
\hline Média & & 11,9 & & 8,2 & & 13,4 & & 10,1 \\
\hline
\end{tabular}

Fonte: Elaboração própria com base em dados da PNAD/IBGE de 2001 e 2013.

A coluna de frequência apresenta o percentual de pessoas em cada faixa salarial, com os respectivos anos de estudo na coluna seguinte. O setor público apresenta em todas as faixas salariais anos de estudo superiores aos anos de estudo do setor privado (respectivamente, média de 11,9 e 8,2 anos de estudo em 2001; e média de 13,4 e 10,1 em 2013), ou seja, em média três anos de estudos a mais.

Percebe-se que, de 2001 para 2013, houve um aumento nos anos de estudo em todas as faixas salariais e, na média, o setor público aumentou $12,6 \%$, o que equivale a 1,5 anos, enquanto o setor privado aumentou 1,9 anos, o que representa $23,2 \%$.

A diferença do posicionamento dos empregados por faixa salarial é percebida claramente no Gráfico 3, que mostra a frequência de empregados do setor público e privado de acordo com as faixas salariais no ano de 2013. Nota-se que, na faixa até dois salários mínimos, existe uma maior frequência de empregados do setor privado. A partir de dois salários mínimos, a situação é invertida, o setor público passa a ter um maior número de empregados, o que justifica o fato da renda média ponderada do funcionalismo público ser bastante superior a dos empregados privados, como mostrado na Tabela 3. 
O setor público apresenta um maior percentual de pessoas nas faixas de salários mais elevados, 46,7\% dos empregados estão na faixa acima de dois salários mínimos, enquanto, no setor privado, tem apenas $18,1 \%$ dos empregados nestas faixas salariais.

Gráfico 3 - Frequência de empregados por faixa salarial do rendimento per capita - setor público e setor privado, Brasil (2013)

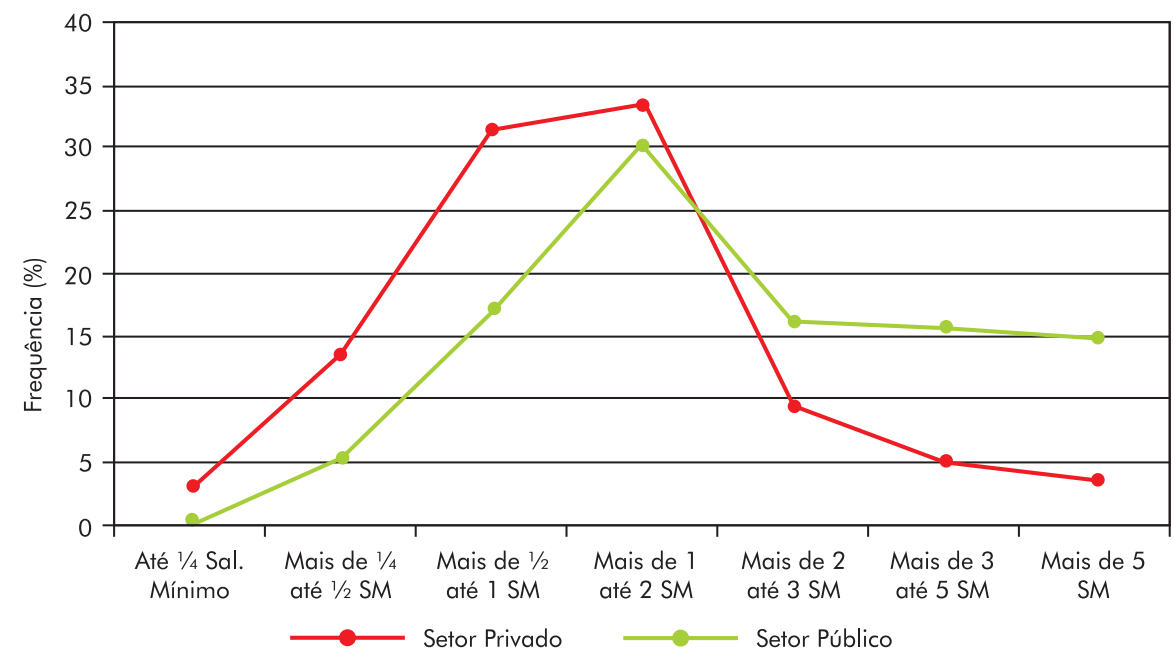

Fonte: Elaboração própria com base em dados da PNAD/IBGE de 2013.

Outra análise separa o rendimento masculino e feminino, desta vez utilizando o rendimento mensal de todos os trabalhos, para que seja possível captar o rendimento individual - o que não seria possível com o rendimento domiciliar per capita. Os resultados, mostrados na Tabela 5, sugerem que, em todas as posições de ocupação no trabalho, exceto no militar, as mulheres têm um rendimento inferior aos homens. Em média, o rendimento masculino em 2001 era 34,9\% superior ao rendimento feminino. Em 2013, a diferença caiu, mas continua 28\% acima do rendimento feminino. A única exceção é a renda média na ocupação de militar, em que o rendimento feminino supera a renda média masculina, mas a quantidade de mulheres envolvidas nesta ocupação é insignificante, apenas 0,06\% das mulheres.

Em contrapartida, em todas as posições de ocupação, as mulheres têm mais anos de estudos do que os homens: em média as mulheres estudaram 1,4 anos em 2001 e 1,3 anos em 2013, a mais que os homens. Na posição de empregado sem carteira de trabalho assinada, as mulheres têm três anos de estudos a mais do que o sexo masculino nos dois anos analisados. A diferença diminuiu de 2001 a 2013, mas ainda permanece em 13,6\%, 
o número médio de anos estudados pelas mulheres a mais que os homens. A situação é contraditória, pois se espera que mais anos de estudos resultem em uma remuneração melhor, no entanto, o fator "sexo" é mais forte que o fator "anos de estudos".

Tabela 5 - Rendimento médio dos empregados e anos de estudo - por sexo e por posição na ocupação no trabalho principal dos empregados, Brasil (2001 e 2013)

\begin{tabular}{|c|c|c|c|c|c|c|}
\hline \multirow{3}{*}{ Descrição } & \multicolumn{3}{|c|}{2001} & \multicolumn{3}{|c|}{2013} \\
\hline & \multicolumn{3}{|c|}{ Renda Média } & \multicolumn{3}{|c|}{ Renda Média } \\
\hline & Masculino & Feminino & \% Dif. & Masculino & Feminino & \% Dif. \\
\hline Empregado com carteira assinada & $1.376,92$ & $1.096,09$ & $-20,4$ & $1.640,13$ & $1.335,94$ & $-18,5$ \\
\hline Militar & $2.457,09$ & $4.465,31$ & 81,7 & $2.508,35$ & $3.870,91$ & 54,3 \\
\hline Funcionário público estatutário & $2.580,85$ & $1.765,24$ & $-31,6$ & $3.455,82$ & $2.445,65$ & $-29,2$ \\
\hline Empregado sem carteira assinada & 732,28 & 711,18 & $-2,9$ & $1.091,15$ & $1.003,42$ & $-8,0$ \\
\hline Trab. doméstico com carteira assinada & 635,00 & 539,83 & $-15,0$ & 979,44 & 834,24 & $-14,8$ \\
\hline Trab. doméstico sem carteira assinada & 430,78 & 334,64 & $-22,3$ & 719,16 & 513,36 & $-28,6$ \\
\hline Média & $1.253,70$ & 929,27 & $-25,9 \%$ & $1.637,59$ & $1.279,33$ & $-21,9 \%$ \\
\hline \multirow{2}{*}{ Descrição } & \multicolumn{3}{|c|}{ Anos de Estudos } & \multicolumn{3}{|c|}{ Anos de Estudos } \\
\hline & Masculino & Feminino & \% Dif. & Masculino & Feminino & \% Dif. \\
\hline Empregado com carteira assinada & 8,6 & 10,6 & 23,0 & 10,2 & 11,8 & 16,1 \\
\hline Militar & 11,6 & 15,4 & 31,9 & 12,3 & 14,8 & 20,4 \\
\hline Funcionário público estatutário & 11,2 & 12,4 & 10,5 & 12,8 & 13,9 & 8,7 \\
\hline Empregado sem carteira assinada & 6,5 & 9,5 & 46,4 & 8,2 & 11,2 & 36,7 \\
\hline Trab. doméstico com carteira assinada & 5,3 & 6,3 & 18,6 & 7,1 & 8,0 & 12,4 \\
\hline Trab. doméstico sem carteira assinada & 5,0 & 5,9 & 17,3 & 6,1 & 7,5 & 21,9 \\
\hline Média & 8,0 & 9,4 & $17,4 \%$ & 9,8 & 11,1 & $13,6 \%$ \\
\hline
\end{tabular}

Fonte: Elaboração própria com base em dados da PNAD/IBGE de 2001 e 2013.

Uma explicação apresentada por Freisleben e Bezerra (2012) para a diferença salarial em favor dos homens, apesar de as mulheres estarem mais escolarizadas, diz respeito à discriminação no mercado de trabalho, uma vez que o diferencial salarial não é explicado pelo de atributos.

Para analisar a diferença salarial e escolaridade por gênero, de maneira mais detalhada, considerou-se o código de ocupação de trabalho, em que homens e mulheres estavam exercendo suas atividades em 2013. Como a quantidade de códigos é elevada, elegeram-se 17 códigos que representam quase $50 \%$ dos homens e $58 \%$ das mulheres envolvidas no mercado de trabalho. Assim, é possível verificar o percentual de homens e mulheres atuando em um mesmo código, com suas respectivas remunerações e escolaridades. 
A Tabela 6 mostra os dados desta análise, ordenada pela frequência feminina ocupada em cada código. Para a maioria dos códigos de ocupação de trabalho, persiste a mesma situação, as mulheres possuem mais anos de estudos, mas recebem menos que os homens por seu trabalho. No caso dos "trabalhadores dos serviços domésticos em geral", verifica-se o maior percentual de mulheres envolvidas, $16 \%$, contra apenas $1 \%$ de homens, embora a diferença salarial seja de $25 \%$ em favor dos homens, mesmo sendo as mulheres 20\% mais escolarizadas. Mesmo nas funções que apresentam uma frequência significativa tanto de homens quanto de mulheres, como "vendedores e demonstradores de loja" e "escriturários e auxiliares administrativos", as mulheres possuem mais anos de estudos, mas recebem praticamente $1 / 4$ a menos da remuneração dos homens.

\section{Tabela 6 - Renda média e anos de estudo por código de ocupação de trabalho e gênero, Brasil (2013)}

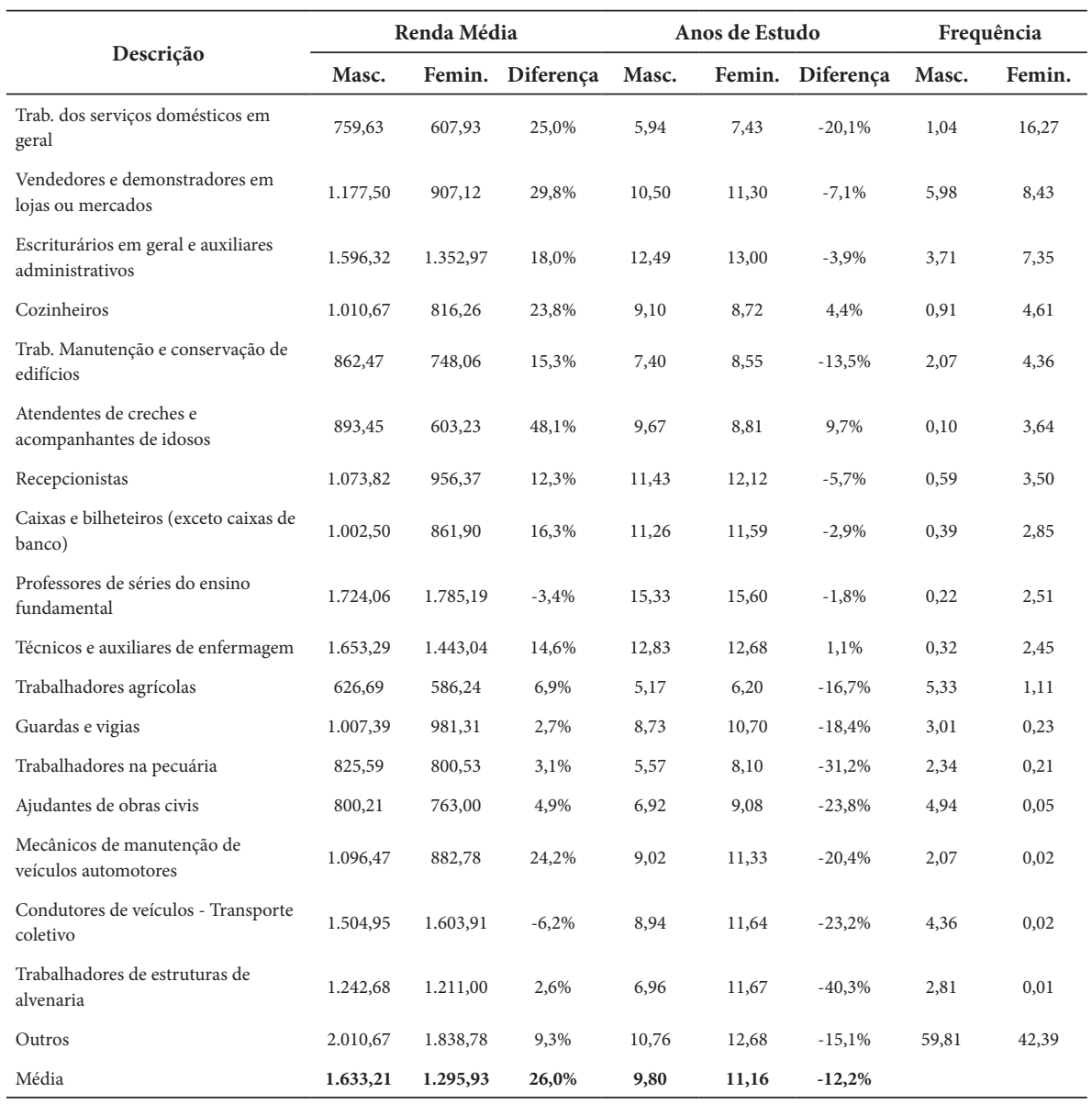

Fonte: Elaboração própria com base em dados da PNAD/IBGE de 2013. 
Apenas na função de "cozinheiros" o sexo masculino apresenta escolaridade acima do feminino, talvez pelo fato de alguns homens que exercem esta função dedicarem-se aos estudos para se tornarem profissionais, enquanto boa parte das mulheres exerce pela experiência doméstica adquirida desde a infância.

A participação relativa de homens e mulheres nas ocupações de trabalho analisadas pode ser vista por meio do Gráfico 4, que exibe a frequência por sexo nas diversas ocupações. É possível verificar que, em 2013, 20\% das mulheres são trabalhadoras domésticas com ou sem carteira assinada, enquanto apenas 1,4\% dos homens estão nesta ocupação de trabalho, que exige menor grau de escolaridade e oferece as menores remunerações. Em 2001, este percentual para as mulheres era de 26,6\%, indicando que houve uma redução do trabalho doméstico, em especial, o trabalho doméstico sem carteira assinada.

\section{Gráfico 4 - Frequência do sexo por posição na ocupação no trabalho principal dos empregados, Brasil (2001 e 2013)}

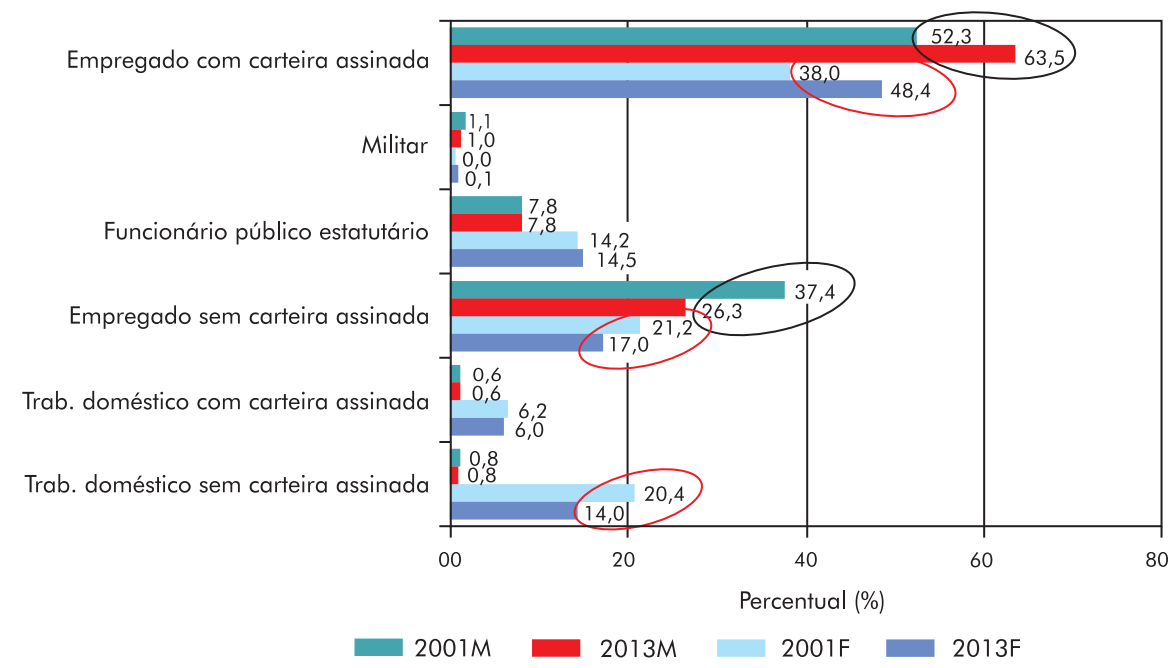

Fonte: Elaboração própria com base em dados da PNAD/IBGE de 2001 e 2013.

Observa-se que houve um aumento significativo de empregados com carteira assinada, tanto entre homens quanto entre mulheres, que passou de 52,3\% para $63,5 \%$ no caso dos empregados masculinos, e de $38 \%$ para $48,4 \%$ no feminino. No caso masculino, este aumento foi compensado pela redução de $37,4 \%$ para $26,3 \%$ ocorrida no emprego sem carteira assinada. Isto confirma o que foi apresentado na Tabela 1 sobre a decomposição do Índice de Gini, em que ocorreu uma redução na participação e na razão de concentração dos empregados sem carteira de trabalho assinada, indicando 
que aconteceu um deslocamento de pessoas que trabalhavam sem carteira assinada e que passaram para a categoria de trabalhadores com carteira assinada.

No caso das mulheres, o aumento ocorrido no trabalho com carteira assinada, não foi totalmente compensado pela redução do trabalho sem carteira assinada, que caiu apenas de 21,2\% para 17\%, mas houve diminuição, também, no trabalho doméstico sem carteira assinada, de 20,4\% para 14\%, sugerindo-se que sobreveio uma melhora nas condições de trabalho dos empregados, que passaram a desfrutar legalmente de mais direitos trabalhistas com as carteiras assinadas.

\section{CONSIDERAÇÕES FINAIS}

Diante das análises realizadas, na tentativa de verificar as desigualdades na distribuição de rendimento entre os empregados do setor público e setor privado da economia brasileira no período de 2001 e 2013, foram detectados alguns pontos importantes que merecem destaque.

No período analisado, ocorreu uma melhora na distribuição de renda da economia, o Índice de Gini caiu de 0,571 para 0,506. A razão de concentração do rendimento dos empregados também diminuiu de 0,537 para 0,500, entre 2001 e 2013.

A participação dos rendimentos dos empregados em relação à renda total aumentou de $50,8 \%$ para 53,1\% entre 2001 e 2013, enquanto a participação do rendimento do trabalho caiu de $74,5 \%$ para $73,9 \%$, respectivamente, implicando que houve uma diminuição do rendimento de quem trabalha por conta própria e dos empregadores. Nos dois anos, o rendimento do setor público representa em torno de $20 \%$ da renda dos empregados e é uma parcela de renda regressiva, que contribui para aumentar a concentração de rendas, ou seja, aumenta a desigualdade de rendas. Os outros $80 \%$ que se referem à renda do setor privado constituem uma renda progressiva, pois reduzem a concentração de rendas; entre eles, o trabalhador doméstico correspoden à parcela de rendimento que mais contribui para reduzir as desigualdades, porém com pequena influência, de apenas 1\% na composição do Índice de Gini do setor privado.

A razão de concentração da distribuição de rendimento do setor público aumentou de 0,730 para 0,744 , enquanto a do setor privado caiu de 0,489 para 0,438 , o que demonstra que a distribuição de renda entre o funcionalismo público é mais desigual que entre os empregados privados.

Nos dois anos analisados, 2001 e 2013, os grupamentos de atividades com maiores participações no rendimento total dos empregados são: educação, saúde e serviços sociais; administração pública; comércio e reparação; e indústria de transformação. Destes, os dois primeiros referem-se, basicamente, a empregados do setor público que, con- 
forme análise realizada, avaliam-se como regressivos, e os dois últimos referem-se, inerentemente, a empregados do setor privado, os quais são considerados progressivos.

O rendimento médio do setor público é quase o dobro do rendimento médio do setor privado ( $\mathrm{R} \$ 2.030,00$ e 1.029,00 respectivamente) e, em todos os níveis de instrução, o setor público tem uma remuneração maior que o setor privado, e quase metade dos funcionários públicos, 48,1\% em 2013, possuem curso superior.

Por fim, as mulheres têm mais anos de estudos do que os homens em todas as posições de ocupação. Em média, as mulheres estudaram 17,4\% e 13,6\% a mais, em 2001 e 2013, respectivamente, do que os homens. Porém, o rendimento médio feminino é inferior ao rendimento masculino, em média 25,9\% em 2001 e 21,9\% em 2013.

Diante do exposto, fica evidente que boa parte do diferencial salarial entre os setores público e privado pode ser explicada pela melhor escolaridade dos funcionários públicos, que por possuírem um nível de escolaridade mais elevado recebem uma melhor remuneração. Porém, o mesmo não pode ser dito em relação à diferença salarial entre gênero, pois a remuneração maior recebida pelos homens não é explicada pela diferença de escolaridade, sugerindo a existência de discriminação no mercado de trabalho.

\section{REFERÊNCIAS BIBLIOGRÁFICAS}

ANDRADE, T. Mulheres no mercado de trabalho: onde nasce a desigualdade? Estudo Técnico - Consultoria Legislativa, Brasília, jul. 2016.

BARROS, R. P.; CURY, S.; ULYSSEA, G. A desigualdade de renda no Brasil encontra-se subestimada? Uma análise comparativa com base na PNAD, na POF e nas Contas Nacionais. Texto de Discussão, IPEA, Rio de Janeiro, n. 1.263, 2007.

BARROS, R. P.; LAM, D. Desigualdade de renda, desigualdade em educação e escolaridade das crianças no Brasil. Pesquisa e Planejamento Econômico, Rio de Janeiro, v. 23, n. 2, p. 191-218, ago. 1993.

BRAGA, B.; FIRPO, S.; GONZAGA, G. Escolaridade e diferencial de rendimentos entre o setor privado e o setor público no Brasil. Pesquisa e Planejamento Econômico, São Paulo, v. 39, n. 3, dez. 2009.

BRASIL, R. G. Hiato de rendimentos público-privado: decomposição quantílica inter-regional, 2004 - 2013. Dissertação (Mestrado em Desenvolvimento Econômico) - Departamento de Economia, Universidade Federal do Paraná, Curitiba, 2016.

DARÉ, E. F.; HOFFMANN, R. Desigualdade da distribuição de renda no Brasil: A contribuição dos rendimentos do funcionalismo público. Mercado de Trabalho, IPEA, São Paulo, n. 53, nov. 2012.

DARÉ, E. F.; HOFFMANN, R. Remuneração do funcionalismo público e a variação da desigualdade da distribuição da renda no Brasil de 1995 a 2009. Econ Papers, v. 14, n. 1, p. 645-670, 2013. 
FERREIRA, C. F. Aposentadorias e distribuição da renda no Brasil: uma nota sobre o período de 1981 a 2001. RBE, Rio de Janeiro, v. 60, n. 3, p. 247-260, jul./set. 2006.

FERREIRA, C. R.; SOUZA, S. C. I. "Aposentadorias e pensões" e desigualdade da renda: uma análise para o Brasil no período 1998-2003. Revista Economia Contemporânea, Rio de Janeiro, v. 12, n. 1, p. 41-66, jan./abr. 2008.

FREISLEBEN, V. S.; BEZERRA, F. M. Ainda existe discriminação salarial contra as mulheres no mercado de trabalho da região Sul do Brasil? Evidências para os anos de 1998 e 2008. Revista Cadernos de Economia, Chapecó, v. 16, n. 30-31, p. 51-65, dez. 2012.

HOFFMANN, R. A distribuição da renda no Brasil no período 1992-2001. Economia e Sociedade, Campinas, v. 11, n. 2, p. 213-235, jul./dez. 2002.

HOFFMANN, R. Transferências de renda e a redução da desigualdade no Brasil e cinco regiões entre 1997-2004. Econômica, Niterói, v. 8, p. 55-81, 2006.

HOFFMANN, R. Desigualdade da distribuição da renda no Brasil: a contribuição de aposentadorias e pensões e de outras parcelas do rendimento domiciliar per capita. Economia e Sociedade, Campinas, v. 18, n. 1, p. 213-231, abr. 2009.

HOFFMANN, R. Desigualdade e polarização entre empregados na agricultura brasileira: 19922007. Economia e Sociedade, v. 18, n. 2, p. 417-428, ago. 2009.

HOFFMANN, R. Desigualdade de renda e das despesas per capita no Brasil entre 2002-2003 e 2008-2009, e avaliação do grau de progressividade de parcelas da renda familiar. Economia e Sociedade, Campinas, v. 19, n. 3 (40), p. 647-661, dez. 2010.

HOFFMANN, R.; NEY, M. G. A recente queda da desigualdade de renda no Brasil: análise de dados da PNAD, do Censo Demográfico e das Contas Nacionais. Econômica, Rio de Janeiro, v. 10, n. 1, p. 7-37, jun. 2008a.

HOFFMANN, R.; NEY, M. G. A contribuição das atividades agrícolas e não-agrícolas para a desigualdade de renda no Brasil rural. Economia Aplicada, São Paulo, v. 12, n. 3, p. 365-393, jul/set. 2008b.

IBGE - INSTITUTO BRASILEIRO DE GEOGRAFIA E ESTATÍSTICA. Síntese de Indicadores Sociais: Uma análise das condições de vida da população brasileira 2013. Estudos \& Pesquisa, IBGE, Rio de Janeiro, n. 32, 2013.

IBGE - INSTITUTO BRASILEIRO DE GEOGRAFIA E ESTATÍSTICA. Pesquisa Nacional por Amostra de Domicílios. Disponível em: <http://www.ibge.gov.br>. Acesso em: 25 set. 2014.

LAM, D.; LEVISON, D. Idade, experiência, escolaridade e diferenciais de renda: Estados Unidos e Brasil. Pesquisa e planejamento Econômico, Rio de Janeiro, v. 20, n. 2, p. 219-256, ago. 1990.

LAM, D.; SCHOENI, R. F. Effects of family background on earnings and returns to schoolong: evidence from Brazil. Journal of Political Economy, University of Chicago, v. 101, n. 4, 1993.

LEMOS, J. J. S. Assimetria na escolaridade induz desigualdades na distribuição de renda no Brasil. Revista Econômica do Nordeste, Fortaleza, v. 40, n. 3, jul-set. 2009.

MARIANO, J. L.; LIMA, R. C. A desigualdade da renda rural no Nordeste: análise da desagregação do coeficiente de Gini e da sensibilidade do índice de bem-estar de Sen. Análise Econômica, v. 16, n. 29, p. 103-118, mar. 1998 
NEDER, H. D. Os efeitos das atividades não-agrícolas na distribuição de renda no meio rural (CD). In: CONGRESSO BRASILEIRO DE ECONOMIA E SOCIOLOGIA RURAL, 39, Recife, 2001. Anais. Brasília: Sober, 2001.

NERI, M. Causas da queda recente da desigualdade. Conjuntura Econômica, v. 61, n. 3, p.41-43, mar. 2007.

PIKETTY, T. O Capital no século XXI. Rio de Janeiro: Intrínseca, 2014.

PYATT, G.; CHEN, C.; FEI, J. The distribution of income by factor components. The Quarterly Journal of Economics, v. 95, n. 3, p. 451-473, nov. 1980.

RAMOS, L. "Desigualdade de rendimentos do trabalho no Brasil, de 1995 a 2005". In: BARROS, R. P.; FOGUEL, M. N.; ULYSSEA, G. (Orgs.). Desigualdade de renda no Brasil: uma análise da queda recente. Brasília: IPEA, v. 2, p. 267-284, 2007.

REIS, M. C.; RAMOS, L. Escolaridade dos pais, desempenho no mercado de trabalho e desigualdade de rendimentos. Revista Brasileira de Economia, Rio de Janeiro, v. 65, n. 2, p. 177 205, abr/jun. 2011.

ROCHA, R.; URANI, A. Posicionamento social e a hipótese da distribuição de renda desconhecida. Brasil: quão pobres, quão ricos e quão desiguais nos percebemos? Revista de Economia Política, v. 27, n. 4, p. 595-615, out./dez. 2007.

ROSSI, J. W. Decomposição funcional do índice de Gini com dados de renda do Brasil. Revista Brasileira de Economia, Rio de Janeiro, v. 37, n. 3, p. 337-348, jul./set. 1983.

SALVATO, M. A.; FERREIRA, P. C. G.; DUARTE, A. J. M. O impacto da escolaridade sobre a distribuição de renda. Estudos Econômicos, São Paulo, v. 40, n. 4, p. 753-791, out./dez. 2010.

SANTANA, J. A. A evolução dos programas de transferências de renda e o Programa Bolsa Família. Seminário População, Pobreza e Desigualdade, Belo Horizonte, nov. 2007. Disponível em: <www.renda.nepp.unicamp.br/sistema/files/brasil/abep_1019.pdf>. Acesso em: 18 out. 2015.

SOARES, S. S. D. Distribuição de renda no Brasil de 1976 a 2004 com ênfase no período de 2001 e 2004. Texto para Discussão, IPEA, Rio de Janeiro, n. 1.166, 2006.

SOUZA, P. H. G. F.; MEDEIROS, M. Diferencial salarial público-privado e desigualdade de renda per capita no Brasil. Estudos Econômicos, São Paulo, v. 43, n. 1, p. 5-28, 2013. 